\title{
Antibacterial Activities of Isothiocyanates Extracted from Horseradish (Armoracia rusticana) Root against Antibiotic-resistant Bacteria
}

\author{
Hee-Yun Kim, Sarinnart Phan-a-god, and Il-Shik Shin
}

Received October 27, 2014; revised February 2, 2015; accepted February 3, 2015; published online June 30, 2015

(C) KoSFoST and Springer 2015

\begin{abstract}
The antibacterial activities of isothiocyanates (ITCs) extracted from horseradish root was determined against 4 strains of antibiotic-resistant bacteria, methicillinresistant Staphylococcus aureus (MRSA), vancomycinresistant $S$. aureus (VRSA), multidrug-resistant Acinetobacter baumanii (MRAB), and multidrug-resistant Pseudomonas aeruginosa (MRPA), and 3 strains of normal pathogenic bacteria, S. aureus, A. baumanii, and P. aeruginosa. The minimum bactericidal concentrations (MBC) of ITCs against MRSA, VRSA, MRAB, and MRPA were 666.7, 666.7, 333.3, and $208.3 \mu \mathrm{g} / \mathrm{mL}$, respectively, and against $S$. aureus, A. baumanii, and $P$. aeruginosa were 833.3, 41.7, and $52.1 \mu \mathrm{g} / \mathrm{mL}$, respectively. ITCs extracted from horseradish root showed the strongest antibacterial activity against $A$. baumanii with a MBC of $41.7 \mu \mathrm{g} / \mathrm{mL}$. Among antibioticresistant bacteria, ITCs showed the strongest antibacterial activity against MRPA with a MBC of $208.3 \mu \mathrm{g} / \mathrm{mL}$. MBC values of vancomycin against MRSA, VRSA, and S. aureus were $1,667.7,2,000.0$, and $1,333.3 \mu \mathrm{g} / \mathrm{mL}$, levofloxacin against MRAB and $A$. baumanii were 833.3 and 1,333.3 $\mu \mathrm{g} / \mathrm{mL}$, respectively, norfloxacin against MRPA and $P$. aeruginosa were 666.7 and $7.8 \mu \mathrm{g} / \mathrm{mL}$, respectively. ITCs showed stronger antibacterial activities than antibiotics against tested bacteria except $P$. aeruginosa. These results indicate that ITCs extracted from horseradish root should be candidates for antibacterial agent against antibioticresistant bacteria.
\end{abstract}

Hee-Yun Kim

Department of Foodservice Management, Woosong University, Daejeon 300-715, Korea

Sarinnart Phan-a-god, Il-Shik Shin $(\bowtie)$

Department of Applied Marine Biotechnology and Engineering, Gangneung-Wonju National University, Gangneung, Gangwon 210-702, Korea

Tel: +82-33-640-2346; Fax: +82-33-640-2346

E-mail: shinis@gwnu.ac.kr
Keywords: antibacterial activity, horseradish, isothiocyanate, antibiotic resistant bacteria

\section{Introduction}

Horseradish (Armoracia rusticana) is grown mainly for the root to be used as a condiment and spice for foodstuffs, and formerly used medicinally, particularly as an antiscorbutic (1). When horseradish tissues are damaged by cutting, enzyme from the damaged horseradish plant cells breakdown sinigrin (a glucosinolate) to produce isothiocyantes (ITCs). The characteristic odor and taste of horseradish is due to ITCs formed by the action of myrosinase on glucosinolate when plant tissues are disrupted $(1,2)$.

The major components for antimicrobial activity in horseradish are ITCs. Allyl isothiocyantes (AITC) (3), phenylethyl isothiocyanate (PITC), and other ITCs (4) are contained in ITCs extracted from horseradish root. AITC is known to possess a strong antimicrobial activity, capable of killing fungal and bacterial pathogens on plant seeds and fresh produce (5), bread (6), meat (7), and cheese (8), and to possess antimicrobial effects against Escherichia coli O157:H7, Listeria monocytogenes, Salmonella Typhimurium, and Staphylococcus aureus (9), Staphylococcus sp. (3), and lactic acid bacteria (10). Although applications of ITCs are limited due to a high volatility and poor water solubility $(11,12)$, ITCs have strong antimicrobial activities that are capable of killing fungal and pathogenic bacteria (13). Therefore, it seems reasonable to explore the possibility of ITCs as an antibacterial agent. The antimicrobial activity of ITCs is believed to be due to the inactivation of extracellular enzymes through cleavage of disulfide bonds (14). Several mechanisms including the modulation of SH enzymes, inhibition of RNA synthesis, partial inhibition of 
DNA synthesis, and inhibition of protein synthesis by an action of the ITCs moiety $(-\mathrm{N}=\mathrm{C}=\mathrm{S})$, have been proposed for the antibacterial activity of ITCs (15).

Antibiotic-resistant bacteria in the medical field have been well recognized as a global nosocomial problem in recent years (5). Infections caused by multidrug-resistant bacteria challenge physicians and endanger the lives of patients (16). During the last decade, efforts to combat microorganisms have increased, and drug companies have developed several novel antimicrobial agents. Unfortunately, the growing problem of multidrug resistance in bacteria has not been paralleled by development of novel antimicrobials. A return to the pre-antibiotic era has become a reality in many parts of the world, indicating the poor effects of current antibacterial agents and a lack of newer active antibiotics (17).

Methicillin-resistant $S$. aureus (MRSA) has been identified as an important gram-positive bacterium involved in both hospital-acquired and community-acquired infections. MRSA has become a worldwide concern because it is highly prevalent, capable of developing new clones, resistant to almost all currently available antibiotics except vancomycin and teicoplanin, and can cause death. Clinically-used linezolid and teicoplanin produce undesirable side effects, such as anaphylactoid symptoms, acute renal failure and disruption of liver function (18). Recently, the susceptibility of MRSA to vancomycin has decreased. Thus, an increase in vancomycinresistant $S$. aureus (VRSA) cases has been reported in several countries $(18,19)$. Vancomycin is the last resort anti-MRSA antibiotic (18).

Acinetobacter baumanii, members of the genus Acinetobacter, are gram-negative, aerobic coccobacilli (family Moraxellaceae). Several species are widely distributed in soil and water and may occasionally become part of the normal microbiota of the skin, throat and rectum (20). $A$. baumanii causes nosocomial infections such as bloodstream infections, ventilator-associated pneumonia and wound infections, particularly in critical patients admitted to the intensive care unit (ICU). A. baumanii is characterized by a tendency to acquire resistance to multiple classes of antimicrobial agents $(21,22)$. Most reported A. baumanii outbreaks are due to multidrug-resistant isolates $(16,22,23)$. Resistance to carbapenems has been observed worldwide in the past decade (24) and resistance to fluoroquinolones, aminoglycosides, sulphonamides, and third-generation cephalosporins $(16,25,26)$ has increased.

Pseudomonas aeruginosa is one of the leading causes of bacteremia and pneumonia in patients hospitalized in ICUs. In addition to being intrinsically resistant to several antimicrobial agents, $P$. aeruginosa can acquire resistance to conventional antipseudomonal antibiotics including antipseudomonal penicillins, ceftazidime, carbapenems, aminoglycosides, and fluoroquinolones (27). Resistance to anti-pseudomonal beta-lactams, advanced generation cephalosporins, monobactams, and carbapenems is also an increasing clinical problem (28). P. aeruginosa is one of the most important opportunistic pathogens responsible for various types of infections, especially in patients in intensive care. This organism is remarkably versatile in combining different intrinsic and acquired resistance mechanisms (29), which underlines resistance to multiple antimicrobial agents, a situation that is commonly encountered among hospital $P$. aeruginosa strains. Together with $A$. baumannii and Klebsiella pneumoniae, $P$. aeruginosa is among microorganisms with the greatest mismatch between an unmet medical need for new effective antimicrobials and the current antimicrobial research and development pipeline (30). Therefore, there is an urgent and growing need for development of new antibiotics with novel modes of action to help overcome these problems (18).

In this study, the antibacterial activity of ITCs extracted from horseradish (A. rusticana) root for development of natural antibacterial agents against antibiotic-resistant bacteria, MRSA, VRSA, multidrug-resistant Acinetobacter baumanii (MRAB), and multidrug-resistant Pseudomonas aeruginosa (MRPA) were investigated.

\section{Materials and Methods}

Preparation of extracts To extract ITCs, $1,000 \mathrm{~g}$ of horseradish (A. rusticana) root powder purchased from Biocoats Co. (Seoul, Korea) was mixed with $2,750 \mathrm{~mL}$ of distilled water and allowed to react at $40^{\circ} \mathrm{C}$ in a water bath for $2 \mathrm{~h}$ to produce ITCs from sinigrin in the horseradish. Subsequently, the reacted mixture was distilled and concentrated by rotary evaporator (Rotavapor R-200; BUCHI Co., new Castle, DE, USA) at $120^{\circ} \mathrm{C}$ of oil bath for $120 \mathrm{~min}$. The essential oil (ITCs) was separated from the concentrated solution by centrifugation (Mega 17R; Hanil Science Industrial Co., Seoul, Korea) at 5,000 $\times \mathrm{g}$ for $20 \mathrm{~min}$.

Microorganisms and media Four strains of antibioticresistant bacteria were used for an antibacterial activity assay of ITCs extracted from horseradish (A. rusticana) root. VRSA ATCC 12692 was obtained from the American Type Culture Collection (ATCC, Manassas, VA, USA). MRSA CCARM 3108, MRAB CCARM 12007, and MRPA CCARM 2046 were obtained from the Culture Collection of Antimicrobial Resistant Microbes, Department of Biology, Seoul Women's University, Seoul, Korea. These antibiotic-resistant bacteria were grown in Brain heart infusion (BHI) medium (Difco Co., Detroit, MI, USA) at $37^{\circ} \mathrm{C}$ for $24 \mathrm{~h}$. The 3 normal pathogenic bacteria, S. aureus ATCC 25923, A. baumanii KCCM 35453, and $P$. aeruginosa KCCM 11328 obtained from the Korean 
Culture Center of Microorganisms (KCCM, Seoul, Korea) were grown in $\mathrm{BHI}$ medium at $37^{\circ} \mathrm{C}$ for $24 \mathrm{~h}$.

Paper disk diffusion assay Antibacterial activities of ITCs extracted from horseradish were measured using a paper disk diffusion assay. Bacterial cultures were adjusted to $5.0 \times 10^{7} \mathrm{CFU} / \mathrm{mL}$ using sterile BHI medium, and $100 \mu \mathrm{L}$ of each bacterial culture was spread on the surface of BHI agar (Difco Co.) using a sterile glass rod. After absorption of ITCs $(5,000 \mathrm{mg} / \mathrm{L}, 50 \mu \mathrm{L})$ into an 8-mm Whatman No. 2 filter paper disk (Sigma-Aldrich, St. Louis, MO, USA), the disk was placed on the agar surface and incubated at $37^{\circ} \mathrm{C}$ for $48 \mathrm{~h}$. Antibacterial activity was expressed with diameter $(\mathrm{mm})$ of clear zone (Circumference of filter paper disk).

\section{Minimum inhibitory concentration (MIC) assay MIC} values of ITCs against antibiotic resistant bacteria were determined following the broth microdilution method as described by the Clinical Laboratory Standards Institute (31). ITCs $(2,000 \mu \mathrm{g} / \mathrm{mL})$ extracted from horseradish root were initially dissolved in ethyl alcohol, then serially diluted in a two-fold series with sterilized BHI medium. Each bacterium was adjusted to a concentration of $1.0 \times 10^{7}$ $\mathrm{CFU} / \mathrm{mL}$ using the culture medium, then a $5 \mu \mathrm{L}$ culture was inoculated into each well of a 96-well flat-bottom microplate (Nunc Ltd., Roskilde, Denmark), that had been previously filled with $100 \mu \mathrm{L}$ of medium containing $50 \mu \mathrm{L}$ of different ITCs concentrations. Plates were incubated at $37^{\circ} \mathrm{C}$ for $48 \mathrm{~h}$. Growth of each bacterium was determined based on the absorbance value measured using a microplate reader (EL800; Bio-Tek Instrument Inc., Winooski, VT, USA) at $660 \mathrm{~nm}$. The MIC was defined as the lowest concentration that showed the lowest absorbance. Positive control against MRSA and VRSA was $2,000 \mu \mathrm{g} / \mathrm{mL}$ of vancomycin, and the positive controls against $\mathrm{MRAB}$, and MRPA were $2,000 \mu \mathrm{g} / \mathrm{mL}$ of levofloxacin and $2,000 \mu \mathrm{g} /$ $\mathrm{mL}$ of norfloxacin, respectively. These antibiotics are well known to have antibacterial activities against the antibiotic resistant bacteria used here. The negative control was a mixture of $100 \mu \mathrm{L}$ of sterilized BHI medium and $5 \mu \mathrm{L}$ of each strain inoculum. Sterilized BHI medium was used as a blank.

Minimum bactericidal concentration (MBC) assay MBC values of ITCs against antibiotic resistant bacteria were determined following the method of Bamba et al. (32). A loopful of each bacterial culture lacking visible growth in each 96-well flat-bottom microplate was inoculated onto the culture medium agar plate, and incubated at $37^{\circ} \mathrm{C}$ for $24 \mathrm{~h}$. The MBC value was defined as the lowest concentration that showed no bacterial colony formation on BHI agar plates.

\section{GC-MS analysis of ITCs extracted from horseradish} root ITCs extracted from horseradish root were analyzed to clarify the main active components involved in the antibacterial activity using an Agilent 7890A GC system equipped with an Agilent 5975C mass spectrometer (Agilent Technologies, Santa Clara, CA, USA). ITCs were prepared using dissolution in $n$-hexane at a 1:1 ratio. The hexane fraction was separated using an HP-5 column $(30 \mathrm{~m} \times 0.25$ mm I.D., $0.25 \mu \mathrm{m}$ film thickness; Agilent Technologies) at a column temperature held at $50^{\circ} \mathrm{C}$ for $1 \mathrm{~min}$, then increased to $250^{\circ} \mathrm{C}$ for $3 \mathrm{~min}$. The inlet temperature was $250^{\circ} \mathrm{C}$ for $3 \mathrm{~min}$. Helium was used as a carrier gas at flow rate of $1.0 \mathrm{~mL} / \mathrm{min}$.

\section{Results and Discussion}

Antibacterial activities of ITCs extracted from horseradish root The antibacterial activities of ITCs extracted from horseradish root and positive control antibiotics are shown in Table 1. ITCs at concentrations of more than $2,000 \mu \mathrm{g} / \mathrm{mL}$ showed inhibition effects against MRSA, VRSA, MRAB, and MRPA, and 3 strains of normal bacteria. ITCs $(10,000 \mu \mathrm{g} / \mathrm{mL})$ showed inhibition zones of $85,10,18$, and $11 \mathrm{~mm}$ against MRSA, VRSA, MRAB, and MRPA, respectively. Inhibition zone sizes were 55,32 , and $85 \mathrm{~mm}$ against $S$. aureus, $A$. baumanii and $P$. aeruginosa, respectively (Table 1 ). The positive control vancomycin showed inhibition zones of 35 and $0 \mathrm{~mm}$ against MRSA and VRSA, respectively, while vancomycin showed an inhibition zone of $12 \mathrm{~mm}$ against $S$. aureus. Levofloxacin and norfloxacin showed inhibition zones of 21 and $23 \mathrm{~mm}$ against MRAB and MRPA, respectively, while Levofloxacin showed an inhibition zone of $29 \mathrm{~mm}$ against $A$. baumanii and Norfloxacin showed an inhibition zone of $55 \mathrm{~mm}$ against $P$. aeruginosa.

MIC and MBC ITCs extracted from horseradish root showed potent antibacterial activities based on MIC and $\mathrm{MBC}$ values against all tested antibiotic-resistant bacteria and normal bacteria (Table 2). The MBC values of ITCs against the antibiotic resistant bacteria, MRSA, VRSA, MRAB, and MRPA were 666.7, 666.7, 333.3, and $208.3 \mu \mathrm{g} / \mathrm{mL}$, respectively. The MBC values of ITCs against $S$. aureus, A. baumanii and $P$. aeruginosa were 833.3, 41.7, and $52.1 \mu \mathrm{g} / \mathrm{mL}$, respectively. ITCs extracted from horseradish root showed the strongest antibacterial activity against $A$. baumanii with an $\mathrm{MBC}$ value of $41.7 \mu \mathrm{g} / \mathrm{mL}$. Among antibiotic-resistant bacteria, ITCs showed the strongest antibacterial activity against MRPA with an MBC value of $208.3 \mu \mathrm{g} / \mathrm{mL}$. The MBC values of vancomycin against MRSA, VRSA, and $S$. aureus were 
Table 1. Diameter of inhibition zones of ITCs extracted from horseradish (A. rusticana) root against 7 strains of pathogenic bacteria

\begin{tabular}{|c|c|c|c|c|c|c|c|c|c|}
\hline \multirow{3}{*}{ Bacterial strain } & \multicolumn{9}{|c|}{ Inhibition zone (mm) } \\
\hline & \multirow[b]{2}{*}{ Negative control ${ }^{1)}$} & \multicolumn{3}{|c|}{ Positive control } & \multicolumn{5}{|c|}{ ITCs $(\mu \mathrm{g} / \mathrm{mL})$} \\
\hline & & $\begin{array}{l}\text { Vancomycin } \\
(100 \mu \mathrm{g} / \mathrm{mL})\end{array}$ & $\begin{array}{l}\text { Levofloxacin } \\
(100 \mu \mathrm{g} / \mathrm{mL})\end{array}$ & $\begin{array}{l}\text { Norfloxacin } \\
(500 \mu \mathrm{g} / \mathrm{mL})\end{array}$ & 10,000 & 5,000 & 2,000 & 1,000 & 500 \\
\hline MRSA & 0 & 35 & - & - & 85 & 20 & 9 & 0 & 0 \\
\hline VRSA & 0 & 0 & - & - & 10 & 10 & 10 & 0 & 0 \\
\hline MRAB & 0 & -2) $^{2}$ & 21 & - & 18 & 12 & 11 & 0 & 0 \\
\hline MRPA & 0 & - & - & 23 & 11 & 10 & 10 & 10 & 8 \\
\hline S. aureus & 0 & 12 & - & - & 55 & 17 & 11 & 0 & 0 \\
\hline A. baumanii & 0 & - & 29 & - & 32 & 10 & 10 & 0 & 0 \\
\hline P. aeruginosa & 0 & - & - & 55 & 85 & 11 & 11 & 0 & 0 \\
\hline
\end{tabular}

${ }^{12}$ Sterile distilled water

${ }^{2)}$ Not tested

Table 2. Minimum inhibitory concentration (MIC) and minimum bactericidal concentration (MBC) values of ITCs extracted from horseradish (A. rusticana) root against 7 strains of pathogenic bacteria

\begin{tabular}{lcccccccc}
\hline \multirow{2}{*}{$\begin{array}{c}\text { Bacterial } \\
\text { strain }\end{array}$} & \multicolumn{2}{c}{ Vancomycin $(\mu \mathrm{g} / \mathrm{mL})$} & \multicolumn{2}{c}{ Levofloxacin $(\mu \mathrm{g} / \mathrm{mL})$} & \multicolumn{2}{c}{ Norfloxacin $(\mu \mathrm{g} / \mathrm{mL})$} & \multicolumn{2}{c}{$\mathrm{ITCs}(\mu \mathrm{g} / \mathrm{mL})$} \\
\cline { 2 - 10 } & MIC & MBC & MIC & MBC & MIC & MBC & MIC & MBC \\
\hline MRSA & $13.2 \pm 4.6^{1)}$ & $1,666.7 \pm 577.4$ & - & - & - & - & $666.7 \pm 2888.7$ & $666.7 \pm 288.7$ \\
VRSA & $1,666.7 \pm 577.4$ & $2,000.0 \pm 0.0$ & - & - & - & - & $83.3 \pm 36.1$ & $666.7 \pm 288.7$ \\
MRAB & -2 & - & $6.5 \pm 2.3$ & $833.3 \pm 288.7$ & - & - & $166.7 \pm 72.2$ & $333.3 \pm 144.3$ \\
MRPA & - & - & - & - & $26.1 \pm 9.1$ & $666.7 \pm 288.7$ & $166.7 \pm 72.2$ & $208.3 \pm 72.2$ \\
S. aureus & $26.1 \pm 9.1$ & $1,333.3 \pm 577.4$ & - & - & - & - & $666.7 \pm 288.7$ & $833.3 \pm 288.7$ \\
A. baumanii & - & - & $416.7 \pm 144.3$ & $1,333.3 \pm 577.4$ & - & - & $41.7 \pm 18.0$ & $41.7 \pm 18.0$ \\
P. aeruginosa & - & - & - & - & $3.3 \pm 1.1$ & $7.8 \pm 0.0$ & $41.7 \pm 18.0$ & $52.1 \pm 18.0$ \\
\hline
\end{tabular}

${ }^{1)}$ Mean value \pm standard deviation of triplicate experiments.

${ }^{2)}$ Not tested

1,667.7, 2,000.0, and 1,333.3 $\mu \mathrm{g} / \mathrm{mL}$, respectively. The MBC values of levofloxacin against MRAB and $A$. baumanii were 833.3 and $1,333.3 \mu \mathrm{g} / \mathrm{mL}$, respectively. The $\mathrm{MBC}$ of norfloxacin against MRPA and P. aeruginosa were 666.7 and $7.8 \mu \mathrm{g} / \mathrm{mL}$, respectively. Based on MBC values, ITCs showed stronger antibacterial activities than antibiotics against 7 tested bacteria. The exception was the MBC value against $P$. aeruginosa.

Akinjogunla et al. (33) reported that MIC and MBC values of leaf extracts from Nymphaea lotus against MRSA and VRSA were in the range of 5,000-10,000 $\mu \mathrm{g} / \mathrm{mL}$ and $10,000-30,000 \mu \mathrm{g} / \mathrm{mL}$, respectively. Yuvaraj et al. (34) reported that the MIC value of a crude extract from the seaweed Clodophora glomerata against MRAB was 100 $\mu \mathrm{g} / \mathrm{mL}$. Nascimento et al. (35) reported that MIC values of Jambolan and clove extracts against MRPA were 50,000 $\mu \mathrm{g} / \mathrm{mL}$. Thus, ITCs extracted from horseradish root had stronger antibacterial activities than extracts from $N$. lotus, Jambolan and cloves against MRSA, VRSA, and MRPA. However, an extract from the seaweed, C. glomerata, had as stronger antibacterial activity than ITCs against MRAB.

\section{Active components in ITCs extracted from horseradish} (A. rusticana) root for antibacterial activities ITCs extracted from horseradish root were analyzed using GCMS to identify the main components for antibacterial activities (Fig. 1). ITCs extracted from horseradish root contained the 2 major isothiocyanate derivatives, AITC $(60.857 \%)$ and PITC (35.268\%), and the minor isothiocyanate derivative, 3-butenyl isothiocyanate (BITC, 1.532\%). From the standard curve (data not shown), AITC and PITC concentration in ITCs extracted from horseradish root were calculated. The horseradish extract contained 208,766 $\mu \mathrm{g} /$ $\mathrm{mL}$ of AITC and $72,778 \mu \mathrm{g} / \mathrm{mL}$ of PITC. The active components in ITCs extracted from horseradish root is different from active components in ITCs extracted from wasabi (Wasabia japonica), which contained various ITCs but no PITC in roots, stems, and leaves (36).

In conclusion, ITCs extracted from horseradish ( $A$. rusticana) root showed potent antibacterial activities against all tested antibiotic-resistant bacteria. ITCs were most effective against MRPA with an MBC value of 208.3 $\mu \mathrm{g} / \mathrm{mL}$, followed MRAB with an MBC value of $333.3 \mu \mathrm{g} /$ 


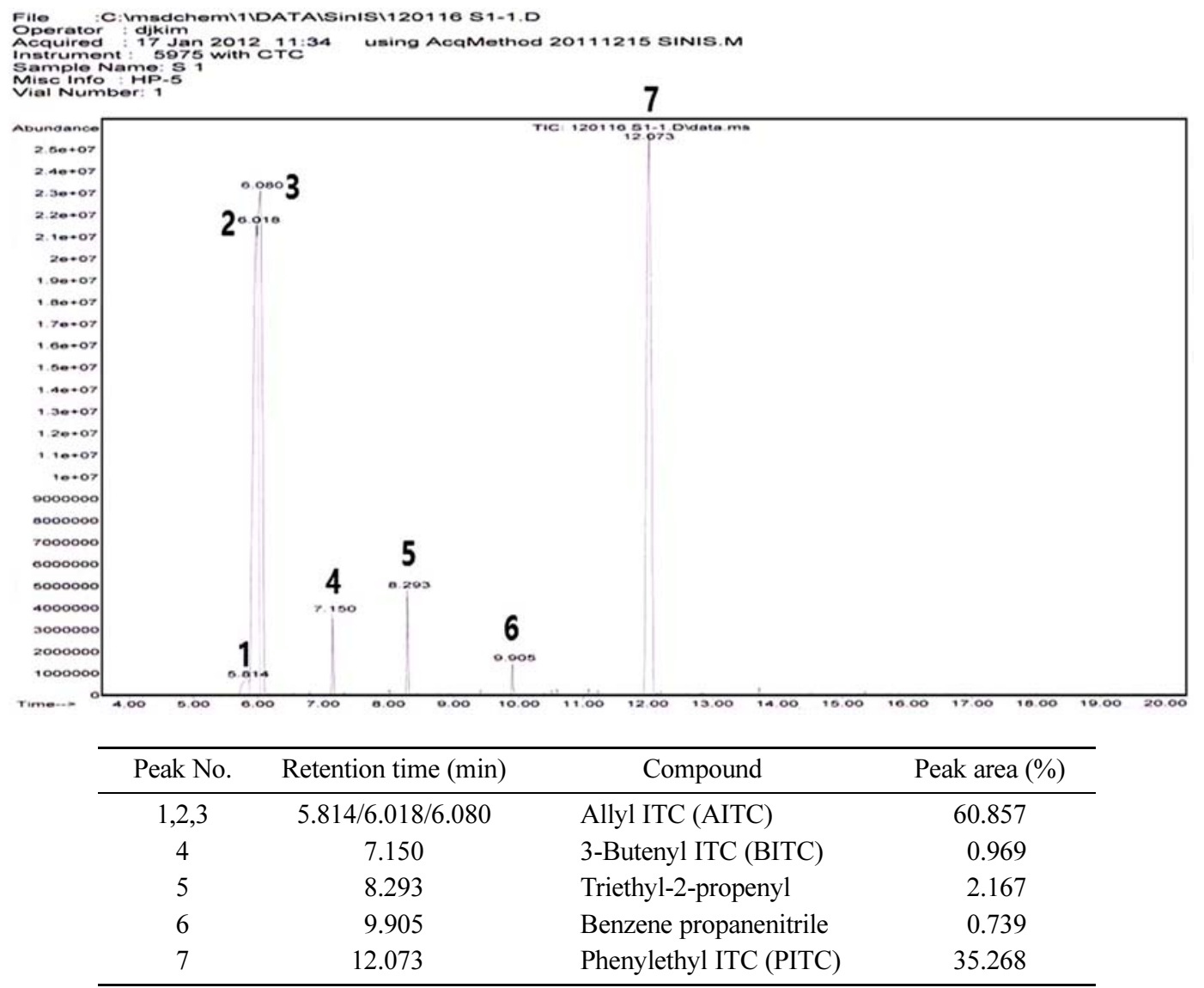

Fig. 1. Analysis of ITCs from horseradish root using GC-MS.

$\mathrm{mL}$. The 2 main components in ITCs extracted from horseradish root were AITC (60.857\%) and PITC (35.268). Thus, the active components in ITCs extracted from horseradish root for antibacterial activity were AITC and PITC. These results indicate that ITCs extracted from horseradish (A. rusticana) root should be candidate for natural antibacterial agents against antibiotic-resistant bacteria.

Disclosure The authors declare no conflict of interest.

\section{References}

1. Fenwick GR, Heaney RK, Mullin WJ, VanEtten CH. Glucosinolates and their breakdown products in food and food plants. CRC $\mathrm{Cr}$. Rev. Food Sci. 18: 123-201 (1982)

2. Chadwick CI, Lumpkin TA, Elberson LR. The botany, uses and production of Wasabia japonica (Miq.) (Cruciferae) Matsum. Econ. Bot. 47: 113-135 (1993)

3. Sikkema J, de Bont JAM, Poolman B. Interactions of cyclic hydrocarbons with biological membranes. J. Biol. Chem. 269: 80228028 (1994)

4. Mazza G. Volatiles in distillates of fresh, dehydrated, and freeze dried horseradish. Can. I. Food Sc. Tech. J. 17: 18-23 (1984)

5. Lee GH, Kang HA, Kim KH, Shin MG. Microencapsulation effects of allyl isothiocyanate with modified starch using fluidized bed processing. Food Sci. Biotechnol. 18: 1071-1075 (2009)
6. Li XH, Jin ZY, Wang J. Complexation of allyl isothiocyanate by $\alpha$ and $\beta$-cyclodextrin and its controlled release characteristics. Food Chem. 103: 461-466 (2007)

7. Nadarajah D, Han JH, Holley RA. Inactivation of Escherichia coli O157:H7 in packaged ground beef by allyl isothiocyanate. Int. J. Food Microbiol. 99: 269-279 (2005)

8. Nielsen PV, Rios R. Inhibition of fungal growth on bread by volatile components from spices and herbs, and the possible application in active packaging, with special emphasis on mustard essential oil. Int. J. Food Microbiol. 60: 219-229 (2000)

9. Shin IS, Han JS, Choi KD, Chung DH, Choi GP, Ahn J. Effect of isothiocyanates from horseradish (Armoracia rusticana) on the quality and shelf life of tofu. Food Control 21: 1081-1086 (2010)

10. Sultana T, McNeil DL, Porter NG, Savage GP. Investigation of isothiocyanate yield from flowering and non-flowering tissues of wasabi grown in flooded system. J. Food Compos. Anal. 16: 637646 (2003)

11. Chacon PA, Buffo RA, Holley RA. Inhibitory effects of microencapsulated allyl isothiocyanate (AIT) against Escherichia coli $\mathrm{O} 157: \mathrm{H} 7$ in refrigerated, nitrogen packed, finely chopped beef. Int. J. Food Microbiol. 107: 231-237 (2006)

12. Kim JH, Park JG, Lee JW, Kim WG, Chung YJ, Byun MW. The combined effects of $\mathrm{N}_{2}$-packaging, heating, and gamma irradiation on the shelf-stability of kimchi, Korean fermented vegetable. Food Control 19: 56-61 (2008)

13. Ko JA, Jeon JY, Park HJ. Preparation and characterization of allyl isothiocyanate microcapsules by spray drying. J. Food Biochem. 36: 255-261 (2012)

14. Kawakishi S, Kaneko T. Interaction of proteins with allyl isothiocyanate. J. Agr. Food Chem. 35: 85-88 (1987)

15. Turgis M, Han J, Caillet S, Lacroix M. Antimicrobial activity of mustard essential oil against Escherichia coli O157:H7 and 
Salmonella typhi. Food Control 20: 1073-1079 (2009)

16. Giamarellou H, Poulakou G. Multidrug-resistant Gram-negative infections: What are the treatment options? Drugs 69: 1879-1901 (2009)

17. Boucher HW, Talbot GH, Bradley JS, Edwards JE, Gilbert D, Rice LB, Scheld M, Spellberg B, Bartlett J. Bad bugs, no drugs: No ESKAPE! An update from the Infectious Diseases Society of America. Clin. Infect. Dis. 48: 1-12 (2009)

18. Kobayash Y, Ichioka M, Hirose T, Nagai K, Matsumoto A, Matsui H, Hanaki H, Masuma R, Takahashi Y, Ômura S, Sunazuka T. Bottromycin derivatives: Efficient chemical modifications of the ester moiety and evaluation of anti-MRSA and anti-VRE activities. Bioorg. Med. Chem. Lett. 20: 6116-6120 (2010)

19. Isnansetyo A, Kamei Y. Anti-methicillin-resistant Staphylococcus aureus (MRSA) activity of $\mathrm{MC}_{21}-\mathrm{B}$, an antibacterial compound produced by the marine bacterium Pseudoalteromonas phenolica $\mathrm{O}$ BC30 ${ }^{\mathrm{T}}$. Int. J. Antimicrob. Ag. 34: 131-135 (2009)

20. Giamarellou H, Antoniadou A, Kanellakopoulou K. Acinetobacter baumannii: A universal threat to public health? Int. J. Antimicrob. Ag. 32: 106-119 (2008)

21. Munoz-Price LS, Weinstein RA. Acinetobacter infection. New Engl. J. Med. 358: 1271-1281 (2008)

22. Peleg AY, Seifert H, Paterson DL. Acinetobacter baumannii: Emergence of a successful pathogen. Clin. Microbiol. Rev. 21: 538$582(2008)$

23. Quale J, Bratu S, Landman D, Heddurshetti R. Molecular epidemiology and mechanisms of carbapenem resistance in Acinetobacter baumannii endemic in New York City. Clin. Infect. Dis. 37: 214-220 (2003)

24. Lee HY, Chen CL, Wang SB, Su LH, Chen SH, Liu SY, Wu TL, Lin TY, Chiu CH. Imipenem heteroresistance induced by imipenem in multidrug-resistant Acinetobacter baumannii: Mechanism and clinical implications. Int. J. Antimicrob. Ag. 37: 302-308 (2011)

25. Karageorgopoulos DE, Falagas ME. Current control and treatment of multidrug resistant Acinetobacter baumannii infections. Lancet Infect. Dis. 8: 751-762 (2008)

26. Vila J, Pachón J. Therapeutic options for Acinetobacter baumannii infections. Expert Opin. Pharmaco. 9: 587-599 (2008)

27. Cholley P, Gbaguidi-Haore H, Bertrand X, Thouverez M, Plésiat P,
Hocquet D, Talon D. Molecular epidemiology of multidrug-resistant Pseudomonas aeruginosa in a French university hospital. J. Hosp. Infect. 76: 316-319 (2010)

28. Patzer JA, Dzierzanowska D. Increase of imipenem resistance among Pseudomonas aeruginosa isolates from a Polish paediatric hospital (1993-2002). Int. J. Antimicrob. Ag. 29: 153-158 (2007)

29. Strateva T, Yordanov D. Pseudomonas aeruginosa A phenomenon of bacterial resistance. J. Med. Microbiol. 58: 1133-1148 (2009)

30. Nemec A, Krizova L, Maixnerova M, Musilek M. Multidrugresistant epidemic clones among bloodstream isolates of Pseudomonas aeruginosa in the Czech Republic. Res. Microbiol. 161: 234-242 (2010)

31. CLSI. Methods for dilution antimicrobial susceptibility tests for bacteria that grow aerobically; approved standard. $5^{\text {th }}$ ed. CLSI document M07-A9. Clinical and Laboratory Standards Institute, Wayne, PA, USA (2012)

32. Bamba H, Kondo Y, Wong RM, Sekine S, Matsuzaki F. Minimum inhibitory concentration of various single agents and the effect of their combinations against Helicobacter pylori, as estimated by a fast and simple in vitro assay method. Am. J. Gastroenterol. 92: 659-662 (1997)

33. Akinjogunla OJ, Yah CS, Eghafona NO, Ogbemudia FO. Antibacterial activity of leave extracts of Nymphaea lotus (Nymphaeaceae) on methicillin resistant Staphylococcus aureus (MRSA) and vancomycin resistant Staphylococcus aureus (VRSA) isolated from clinical samples. Ann. Biol. Res. 1: 174-184 (2010)

34. Yuvaraj N, Kanmani P, Satishkumar R, Paari KA, Pattukumar V, Arul V. Extraction, purification and partial characterization of Cladophora glomerata against multidrug resistant human pathogen Acinetobacter baumannii and fish pathogens. World J. Fish Mar. Sci. 3: 51-57 (2011)

35. Nascimento GGF, Locatelli J, Freitas PC, Silva GL. Antibacterial activity of plant extracts and phytochemicals on antbiotic-resistant bacteria. Braz. J. Microbiol. 31: 247-256 (2000)

36. Etoh H, Nishimura A, Takasawa R, Yagi A, Saito K, Sakata K, Kishima I, Ina K. $\omega$-Methylsulphinylalkyl isothiocyanates in wasabi, Wasabia japonica Matsum. Agr. Biol. Chem. Tokyo 54: 1587-1589 (1990) 